\title{
Erratum to: Variation in Parasympathetic Dysregulation Moderates Short-term Memory Problems in Childhood Attention-Deficit/Hyperactivity Disorder
}

\author{
Anthony R. Ward ${ }^{1}$ - Gabriela Alarcón ${ }^{2}$ - Joel T. Nigg ${ }^{2,3}$ • Erica D. Musser ${ }^{1}$
}

Published online: 26 September 2015

(C) Springer Science+Business Media New York 2015

Erratum to: J Abnorm Child Psychol

DOI 10.1007/s10802-015-0054-3

The authors note two errors in this article. In the reference section, Musser et al. (2014) was mistakenly used whereas the following entry should have been used:

Musser, E. D., Galloway-Long, H. S., Frick, P. J., \& Nigg, J. T. (2013). Emotion regulation and heterogeneity in attentiondeficit/hyperactivity disorder. Journal of the American Academy of Child \& Adolescent Psychiatry, 52(2), 163-171.

Therefore, Musser et al. (2014) is mistakenly cited in the discussion section (fifth paragraph) where Musser et al. (2013) would be the appropriate citation.

Additionally, in the Participants section, readers are mistakenly directed to see Musser et al. (2014) for further details on recruitment and diagnostic procedures, whereas Musser et al. (2011) is the correct citation here (and is included in the reference section of the original article).

The online version of the original article can be found at doi:http://dx.doi. org/10.1007/s10802-015-0054-3.

Anthony R. Ward

arward@fiu.edu

1 Center for Children and Families, Department of Psychology, Florida International University, 11200 SW 8th St., AHC 4 455,

Miami, FL 33199, USA

2 Department of Behavioral Neuroscience, Oregon Health \& Science University, Portland, OR, USA

3 Department of Psychiatry, Oregon Health \& Science University, Portland, OR, USA 